\title{
Effects of sciatic nerve transection on ultrastructure, NADPH-diaphorase reaction and serotonin-, tyrosine hydroxylase-, c-Fos-, glucose transporter 1- and 3-like immunoreactivities in frog dorsal root ganglion
}

\author{
F. Rigon ${ }^{1}$, D. Rossato ${ }^{1}$, V.B. Auler ${ }^{1}$, L. Dal Bosco ${ }^{1}$, M.C. Faccioni-Heuser ${ }^{2,3}$ and W.A. Partata ${ }^{1}$ \\ ${ }^{1}$ Departamento de Fisiologia, Instituto de Ciências Básicas da Saúde, Universidade Federal do Rio Grande do Sul, \\ Porto Alegre, RS, Brasil \\ ${ }^{2}$ Departamento de Ciências Morfológicas, Universidade Federal do Rio Grande do Sul, Porto Alegre, RS, Brasil \\ ${ }^{3}$ Centro de Microscopia Eletrônica, Universidade Federal do Rio Grande do Sul, Porto Alegre, RS, Brasil
}

\begin{abstract}
Frogs have been used as an alternative model to study pain mechanisms. Since we did not find any reports on the effects of sciatic nerve transection (SNT) on the ultrastructure and pattern of metabolic substances in frog dorsal root ganglion (DRG) cells, in the present study, 18 adult male frogs (Rana catesbeiana) were divided into three experimental groups: naive (frogs not subjected to surgical manipulation), sham (frogs in which all surgical procedures to expose the sciatic nerve were used except transection of the nerve), and SNT (frogs in which the sciatic nerve was exposed and transected). After 3 days, the bilateral DRG of the sciatic nerve was collected and used for transmission electron microscopy. Immunohistochemistry was used to detect reactivity for glucose transporter (Glut) types 1 and 3, tyrosine hydroxylase, serotonin and c-Fos, as well as nicotinamide adenine dinucleotide phosphate diaphorase (NADPH-diaphorase). SNT induced more mitochondria with vacuolation in neurons, satellite glial cells (SGCs) with more cytoplasmic extensions emerging from cell bodies, as well as more ribosomes, rough endoplasmic reticulum, intermediate filaments and mitochondria. c-Fos immunoreactivity was found in neuronal nuclei. More neurons and SGCs surrounded by tyrosine hydroxylase-like immunoreactivity were found. No change occurred in serotonin- and Glut1- and Glut3-like immunoreactivity. NADPH-diaphorase occurred in more neurons and SGCs. No sign of SGC proliferation was observed. Since the changes of frog DRG in response to nerve injury are similar to those of mammals, frogs should be a valid experimental model for the study of the effects of SNT, a condition that still has many unanswered questions.
\end{abstract}

Key words: Axotomy; Immunoreactivity; Histochemistry

\section{Introduction}

In amphibians, as in mammals, the dorsal root ganglion (DRG) is composed of three classes of neurons classified according to morphology and function. In addition to neurons, myelinated and unmyelinated fibers, macrophages, fibroblasts, and satellite glial cells (SGCs) are also resident components $(1,2)$. In this ganglion some neurons show reactivity to nicotinamide adenine dinucleotide phosphate diaphorase (NADPH-diaphorase) $(3,4)$, which is considered to be equivalent to nitric oxide (NO) synthase, the enzyme responsible for NO synthesis (5). DRG cells also respond to application of serotonin $(6,7)$ and catecholamine (8).
Amphibians have been used as a model for the study of pain mechanisms (9-15). The reasons for using amphibians in pain research are varied. According to Stevens (9), the use of these animals provides a phylogenetic perspective on the mechanisms of pain research. Other issues include the simplicity of the amphibian central nervous system, the economic advantage of using these animals, and ethical considerations about conducting pain research in non-mammalian vertebrate species. In this context, frog spinal cord and DRG have been used to demonstrate the changes in different neurotransmitters and neuropeptides after sciatic

Correspondence: W.A. Partata, Departamento de Fisiologia, Instituto de Ciências Básicas da Saúde, UFRGS, $90050-170$ Porto Alegre, RS, Brasil. Fax: +55-51-3308-3166. E-mail: partataw@gmail.com 
nerve transection (SNT), one of the models that mimic the clinical conditions of neuropathic pain (16-18). These studies reported alterations that shared similarities with those observed in mammals, while others were unique to this animal species. Moreover, further studies are necessary to better understand the effects of SNT on frog nervous tissue to support the use of this model in this experimental condition.

In mammals, serotonin transporter deficiency attenuated the mechanical allodynia and heat hyperalgesia, symptoms frequently observed in neuropathic pain (19). Tyrosine hydroxylase, a rate-limiting enzyme responsible for catalyzing the conversion of L-tyrosine to the precursor of dopamine and then norepinephrine and epinephrine, shows changes in its immunoreactivity pattern in DRG cells after SNT (20). Glucose transport (Glut) also appears to be modulated by noxious stimuli and denervation (21). These experimental conditions upregulated c-Fos, a protein that is regarded as a marker of neural activation by noxious stimulation (22). SNT also increases $\mathrm{NADPH}$-diaphorase staining in mammalian DRG cells $(23,24)$. SGCs, cells that support DRG neurons both physically and metabolically (25), also change their ultrastructure after peripheral nerve lesion (26).

In order to elucidate the effects of SNT on the ultrastructure and pattern of metabolic substances in bullfrog DRG cells, we used transmission electron microscopy to reveal the effects on the ultrastructure of these cells, and light microscopy to demonstrate the distribution of NADPH-diaphorase reaction and the pattern of Glut1- and Glut3-, serotonin-, tyrosine hydroxylase-, and c-Fos-like immunoreactivity. The experiment was performed 3 days after SNT because previous studies demonstrated that the functional changes in frog nervous tissue are already present 3 days after axotomy (16-18). We think that these findings will determine if these responses are similar across amphibians and mammals, potentially increasing our knowledge of the effects of SNT on frog nervous tissue.

\section{Material and Methods}

\section{Animals}

Eighteen adult male frogs, Rana catesbeiana, weighing 100-200 g were obtained from Ranasul (Brazil). Upon arrival at the laboratory they were housed in cages with water and kept under natural conditions of temperature and photoperiod. The animals were fed specific food ad libitum and acclimated to laboratory conditions for at least 2 weeks before being used. They were divided into 3 experimental groups of 6 animals each: naive (animals did not undergo surgical manipulation), sham (animals in which all surgical procedures to expose the sciatic nerve were used except transection of this nerve), and SNT (animals in which the sciatic nerve was exposed and transected). For the surgical procedures, frogs were anesthetized intramuscularly with $3 \%$ prilocaine (Prilonest ${ }^{\mathbb{B}}$, DFL Indústria e Comércio S.A., Brazil; $0.1 \mathrm{~mL} / 100 \mathrm{~g}$ body weight). In the SNT group, the right sciatic nerve was exposed and transected approximately $5 \mathrm{~mm}$ distal to the sciatic notch. Flexion and ocular reflexes were used to monitor the anesthesic effect. After surgery, the muscle and skin layer were immediately sutured with thread and a topical antibiotic was applied. The animals were killed 3 days after the procedure. The experimental protocol followed the NIH Guide for the Care and Use of Laboratory Animals (NIH publication 85-23, revised 1985) and was approved by the Neuroscience Graduate Committee of Instituto de Ciências Básicas da Saúde, Universidade Federal do Rio Grande do Sul.

\section{Transmission electron microscopy}

The bilateral DRG of the sciatic nerve were dissected out within $3 \mathrm{~min}$ after frog decapitation. They were fixed immediately by immersion in $2 \%$ paraformaldehyde, $1.5 \%$ glutaraldehyde (Sigma, USA) and 0.1 M phosphate buffer (PB), $\mathrm{pH} 7.3$, for $1 \mathrm{~h}$. The material was washed in the same buffer and postfixed in $1 \%$ osmium tetroxide (Sigma) diluted in PB for $1 \mathrm{~h}$ at room temperature. Next, the sections were washed in PB and subsequently dehydrated with an ascending series of acetone, and then embedded in Araldite (Durcupan, Fluka, Switzerland). Semithin sections $(1 \mu \mathrm{M})$ were obtained using an ultramicrotome (MT6000-XL, RMC, USA) with a diamond knife (Diatome, Switzerland) and stained with $1 \%$ toluidine blue for examination under a light microscope. Ultrathin sections $(70 \mathrm{~nm})$ were cut with the same ultramicrotome using a diamond knife (Drukker, The Netherlands). These sections were stained with $2 \%$ uranyl acetate (Merck, Germany) followed by $1 \%$ lead citrate and examined with a JEM 120 EX II electron microscope (Joel, Japan).

\section{Histochemistry and immunohistochemistry}

For the NADPH-diaphorase and immunohistochemical procedure, the frogs were decerebrated and after a brief saline flush they were perfused intracardially with $4 \%$ paraformaldehyde in $0.1 \mathrm{M} \mathrm{PB}, \mathrm{pH}$ 7.4. The DRG were quickly dissected out, immersed in the same fixative solution for $4 \mathrm{~h}$ and then cryoprotected in 15 and 30\% sucrose solutions in $\mathrm{PB}$ at $4^{\circ} \mathrm{C}$. Serial coronal sections $(50 \mu \mathrm{M})$ were obtained with a cryostat and collected in cold phosphate-buffered saline (PBS).

For the NADPH-diaphorase procedure, free-floating sections were pre-incubated in $10 \mathrm{~mL}$ PB containing $12 \mu \mathrm{L}$ Triton $\mathrm{X}-100$ for $10 \mathrm{~min}$. The sections were then transferred to fresh NADPH-diaphorase medium containing $0.5 \mathrm{mg} / \mathrm{mL} \beta-\mathrm{NADPH}, 0.2 \mathrm{mg} / \mathrm{mL}$ nitroblue tetrazolium, and $0.2 \mathrm{M} P B$ containing $12 \mu \mathrm{L}$ Triton X-100. After pre-incubation at room temperature for $5 \mathrm{~min}$ under continuous shaking, they were incubated at $37^{\circ} \mathrm{C}$ for $4 \mathrm{~h}$. The reaction was stopped by the addition of excess 
0.1 M PB. Control sections were incubated in a reaction medium without substrate.

For immunohistochemistry, the sections were treated with $3 \%$ hydrogen peroxide in $10 \%$ methanol for 30 min, washed with PBS for a further $30 \mathrm{~min}$ and incubated for 30 min in 3\% normal goat serum in PBS containing $0.4 \%$ Triton X-100 (PBS-T). The sections were incubated overnight with gentle shaking at $4^{\circ} \mathrm{C}$ with a primary antibody [c-Fos, a polyclonal antibody against 4-17 amino acids, diluted 1:700 (Calbiochem, Germany); Glut1, a polyclonal antibody that recognizes $\sim 42-$ to $45-\mathrm{kDa}$ protein, diluted 1:1000 (Sigma); Glut3, a polyclonal antibody that recognizes the C-terminal sequence of the protein, diluted 1:1000 (Sigma); serotonin, a polyclonal antibody diluted 1:1200 (Sigma); tyrosine hydroxylase, a polyclonal antibody diluted 1:1000 (Calbiochem)]. The primary antibody was then removed and the sections washed in PBS-T for $30 \mathrm{~min}$. The sections were then immersed in a secondary antibody (anti-IgG, Sigma), diluted 1:50 in PBS-T for $2 \mathrm{~h}$ at room temperature with gentle shaking. After washing with PBS-T for $30 \mathrm{~min}$, a peroxidase anti-peroxidase soluble complex andibody (Sigma) diluted 1:500 was applied for $2 \mathrm{~h}$ at room temperature. The samples were then washed in PBS and incubated in a solution of 3,3'-diaminobenzidine tetrahydrochloride (60 mg/100 mL, Sigma) and $0.005 \%(v / v)$ hydrogen peroxide in PBS. Specific immunostaining was abolished when the primary antibody was omitted from the staining sequence.

After the histochemical and immunohistochemical procedures, the sections were mounted onto gelatinized slides, dehydrated, cleared, and covered with Entellan (Merck). The sections were examined and photographed with a Nikon Optiphot-2 microscope equipped with a Nikon FX-35DX camera (Japan).

\section{Results}

In naive animals, DRG neurons had a typical aspect. Ultrastructurally, some neurons exhibited electron-dense cytoplasm while others showed intermediate electron densities. Neuronal cell bodies (Figure 1A) were ensheathed by SGCs. Sometimes only a thin ring of SGC cytoplasm was observed around the soma of the sensory neuron (Figure 1B). In the SGC cytoplasm, there were well-developed rough endoplasmic reticulum (RER), ribosomes and mitochondria (Figures 1 and $2 A-C$ ). Polyribosomes with characteristic rosettes were also found. SGCs had a fusiform shape and were separated from adjacent neurons by a space of about $20 \mathrm{~nm}$. Lamellar cytoplasmic expansions emerging from SGCs and projections from neurons were commonly observed in this space (Figure $1 \mathrm{~A}, \mathrm{~B}$ )

Three days after SNT, several sensory neurons showed increased size, mitochondrial accumulation, and vacuolation in their cytoplasm (Figure 1C). Some mitochondria were so dilated and vacuolated that there were empty spaces (Figure 1D). The nuclei of these neurons began to take an irregular shape. SGCs did not show these changes. The nucleus of SGCs showed a characteristic chromatin condensation, with heterochromatin attached to the nuclear membrane. The nuclear envelope showed regular outlines and no changes were observed in its pores (Figure 2D). A 10-12-nm thick plasma membrane was observed in SGCs and no interruptions along this membrane were seen. Although no statistical analysis was performed, more ribosomes, RER, intermediate filaments, and mitochondria were observed in SGC cytoplasm (Figure 2D-F). Many free ribosomes, polysomes, RER and mitochondria were evenly distributed throughout the SGC cytoplasm, while intermediate filaments (8-10 nm in diameter) were more common in the perinuclear region, which seemed to form a very dense network. Mitochondria and RER generally appeared normal. Mitochondria showed intracristal spaces of normal aspect. While in most cells the RER showed the usual features, sometimes it appeared to be a little dilated. Many lamellar cytoplasmic expansions emerged from SGCs. These expansions had different diameters and lengths and assumed an irregular shape (Figure 3). Although no statistical analysis was performed, the number of SGCs did not seem to be altered after SNT. In the DRG of sham animals, no ultrastructural change was seen in ganglion cells (data not shown).

In naive animals, a strong NADPH-diaphorase reaction occurred in medium and small neurons and in SGCs. In neurons, the positive reaction was more common in medium-sized neurons. The positive SGCs surrounded either positive or non-positive large, medium or small neurons (Figure 4A). Immunoreactivity for c-Fos was found predominantly in the cytoplasm of large and medium neurons (Figure 4C), but no immunoreaction was found in SGCs. Tyrosine hydroxylase-like immunoreactivity was found surrounding neurons (Figure 4E) and SGCs. This glial cell did not show immunoreactivity to serotonin. Some serotonin-like immunoreactivity was found in a few neurons (Figure 5A). While Glut3-like immunoreactivity was found in neurons (Figure 5B), Glut1-like immunoreactivity was located in the capsule of the DRG, blood vessels and SGCs.

SNT also caused changes in histochemical and immunohistochemical patterns. The NADPH-diaphorase reaction was more common in neurons from ipsilateral ganglia. This reaction was strong and prevailed in medium and small neurons (Figure 4B). The number of positive SGCs was also higher after SNT, regardless of whether these cells surrounded positive large, medium or small neurons. Immunoreactivity for c-Fos was found in a larger number of nuclei of sensory neurons (Figure 4D), but it was observed in the cytoplasm of only few neurons. SGCs did not exhibit this immunoreactivity. The number of DRG neurons and SGCs surrounded by tyrosine hydroxylase-like immunoreactivity was also increased after SNT (Figure 4F). However, no change was found in the serotonin immuno- 

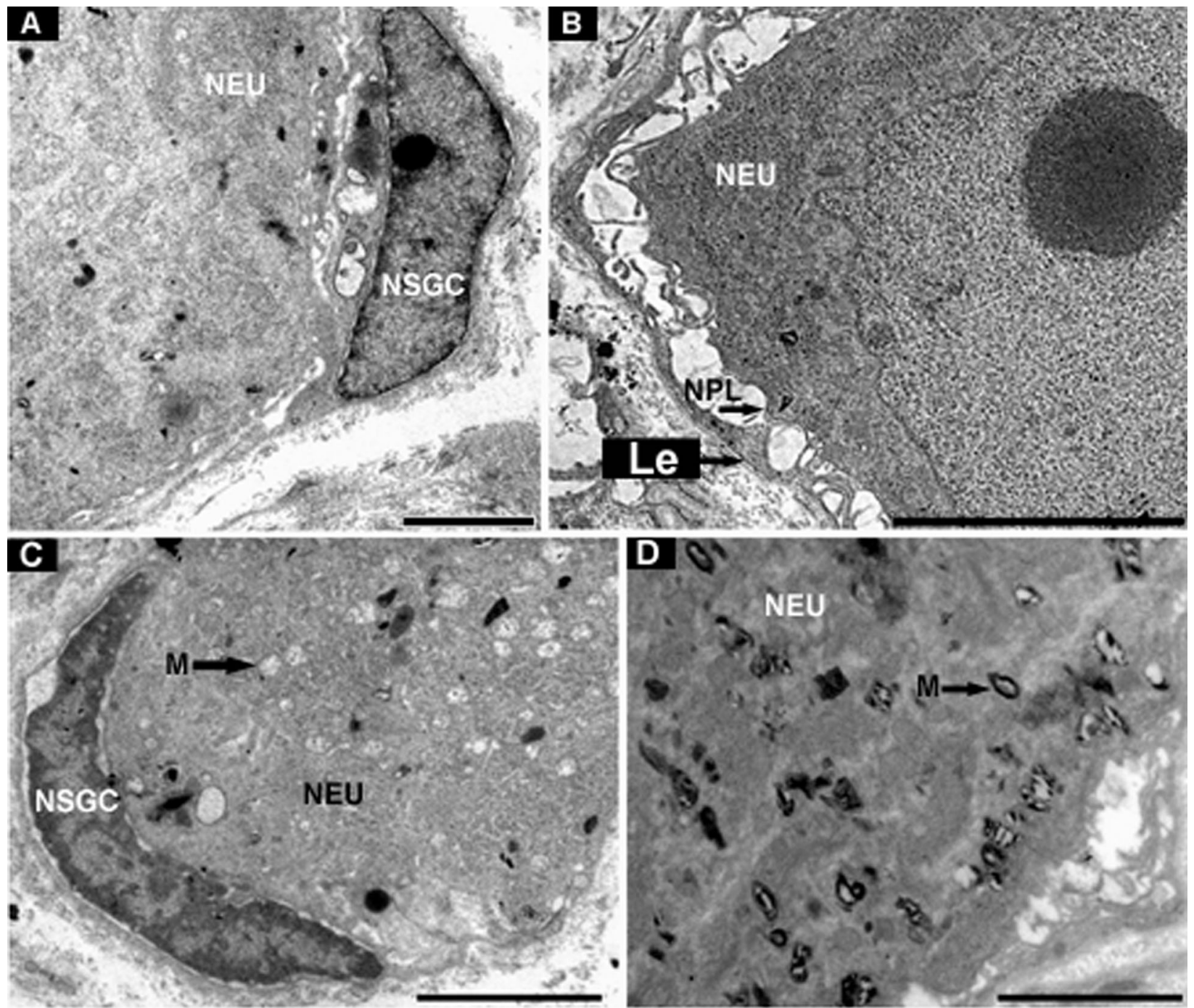

Figure 1. Cross-section of a naive $(A, B)$ and transected $(C, D)$ Rana catesbeiana's dorsal root ganglion. $A$, Nuclear satellite glial cells (NSGC) close to a sensory neuron (NEU). B, Lamellar cytoplasmic expansions (Le) from a satellite glial cell near the neuronal projection (NPL). C, Sensory NEU in the chromatolysis process. Note the mitochondrial (M) accumulation in the neuronal cytoplasm and the characteristic chromatin condensation in the NSGC. $D$, Sensory NEU in the chromatolysis process and vacuolated M. Scale bars: $A(0.2 \mu \mathrm{m}) ; B(5 \mu \mathrm{m}), C$ and $D(2 \mu \mathrm{m})$.

reactivity pattern. Similarly, Glut1 and Glut3 immunoreactivity did not change after SNT (data not shown).

\section{Discussion}

In naive frogs, our results confirmed previous reports (1-4). SNT, in turn, induced prominent morphological changes in the ipsilateral ganglion from axotomized frogs. Most of these changes were similar to those described in mammals. Differently from mammals, however, SNT did not induce proliferation of SGCs 3 days after the surgical procedure in frogs. SGC proliferation appears to be part of the glial responses to nerve injury in mammalian sensory ganglia (26-29). According to Humbertson Jr. et al. (27), the SGC/neuron ratio begins to change on the first day after axotomy, with its value doubling at 6 days and returning to baseline values around day 18. A possible explanation for this difference may be the nervous system's slower metabolic rate in frogs than in mammals (30). If this is true, we can think that the proliferation of SGCs may be occurring in a slower fashion in frog DRG. Clarification of this issue depends on the demonstration of morphological changes in SGCs from axotomized frogs at later times. Research into this matter is underway in our 

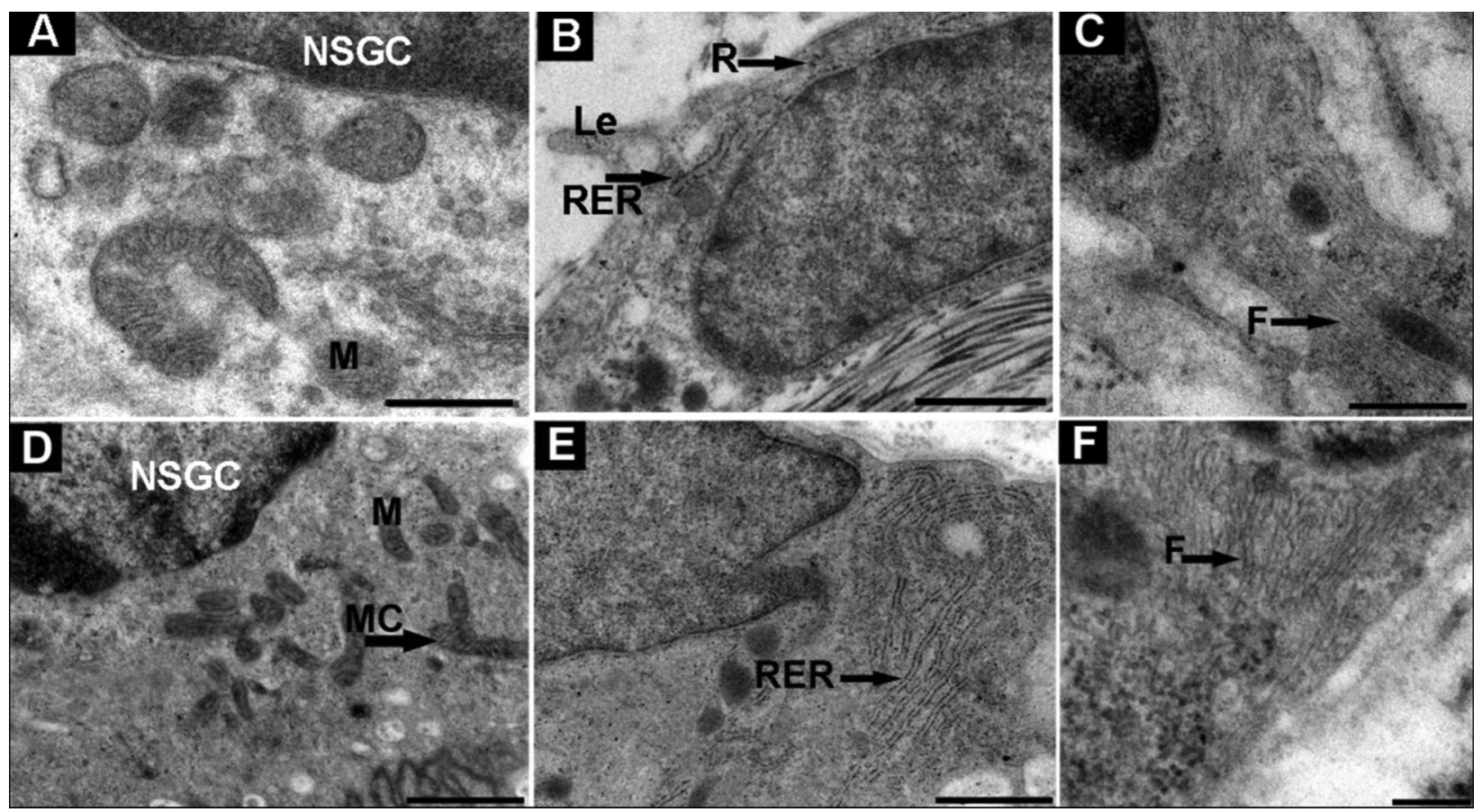

Figure 2. Cross-section of a naive $(A, B, C)$ and transected $(D, E, F)$ Rana catesbeiana's dorsal root ganglion. $A$, Nuclear satellite glial cells (NSGC) with chromatin condensation and heterochromatin attached to the nuclear membrane. Note mitochondria (M) with an intracristal space of normal aspect. $B$ and $C$, Ribosomes (R), rough endoplasmic reticulum (RER) and intermediate filaments (F) in the cytoplasm of satellite glial cell (SGC). Note the lamellar cytoplasmic expansion (Le) emerging from SGC. D, Nucleus of SGC of normal aspect 3 days after sciatic nerve transection. Note the greater number of $\mathrm{M}(D), \mathrm{RER}(E)$ and $\mathrm{F}(F)$ in SGC cytoplasm. MC = tranverse mitochondrial cristae. Scale bars: $A, B, C=0.5 \mu \mathrm{m} ; E$ and $F=1 \mu \mathrm{m} ; D=0.2 \mu \mathrm{m}$.

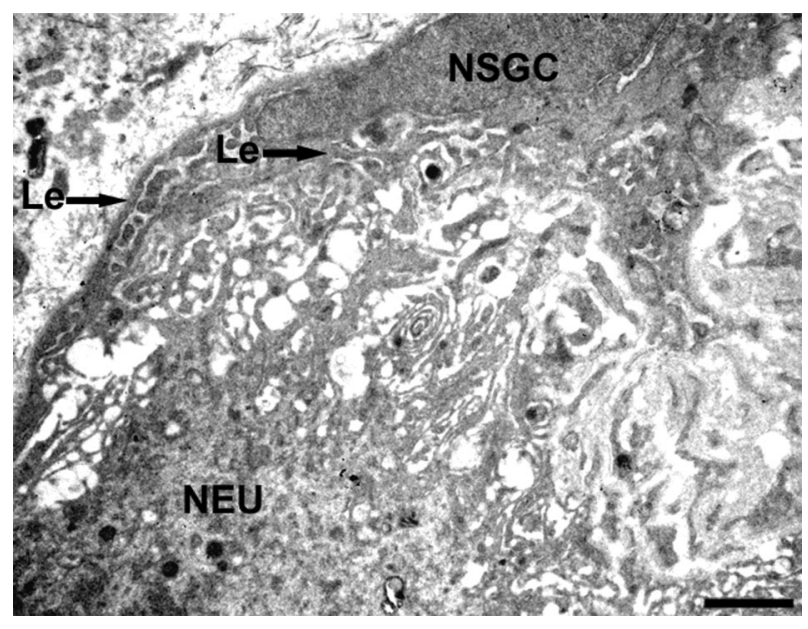

Figure 3. Cross-section of a Rana catesbeiana's dorsal root ganglion 3 days after sciatic nerve transection. Lamellar cytoplasmic expansions (Le) from the cytoplasm of a satellite glial cell (SGC) can be seen, spreading through the interstitial space toward the projections that depart from the neuronal body (NEU). Note chromatin condensation of the nuclear SGC (NSGC). Scale bar $=2 \mu \mathrm{m}$. laboratory. Supportive of the continuation of this research line is the report of increased numbers of SGCs 30 and 90 days after nerve transection in mammals (26).

Some differences between frog and rat responses appear to be common. While moderate neuropeptide $Y$ immunoreactivity was found in normal frog DRG, no immunoreaction to this neuropeptide was observed in rat spinal ganglia. SNT increased neuropeptide $Y$ immunoreaction in ipsilateral and contralateral ganglia of the frogs, while this increase was only seen ipsilaterally in rats (18). It is probable that the differences between frogs and rats represent peculiar responses of frogs. Nevertheless, they do not preclude the use of frogs to study the effects of SNT on nervous tissue. Similar to mammals $(31,32)$, the axotomized frogs' DRG exhibited sensory neurons with enlarged perikarya, swelling in mitochondria and a nuclear membrane with enfolding and indentation. In SGCs there were more intermediate filaments, ribosomes, endoplasmic reticulum, and mitochondria. Histochemical and immunohistochemical changes were also similar to those described in mammals (2,22-24,33-37), with an increase in NADPH-diaphorase reaction and in immunoreactivity to c-Fos and tyrosine hydroxylase, but with no change in serotonin, Glut1 or Glut3 immunoreactivity. Thus, these changes may be playing the same 

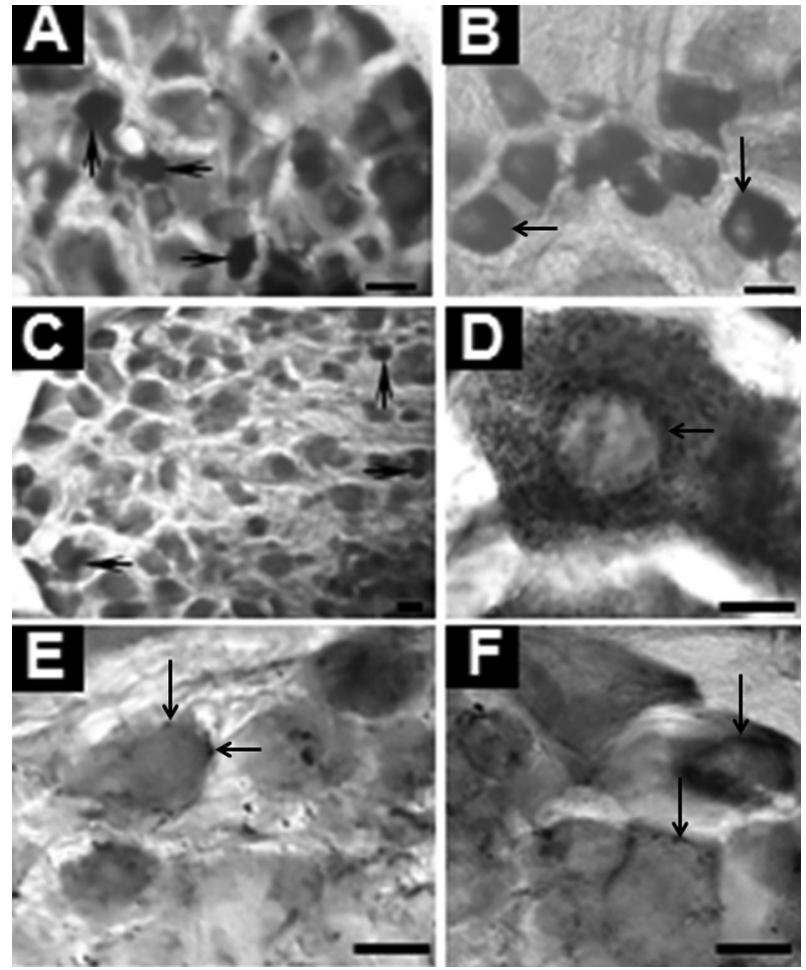

Figure 4. Cross-section of a naive $(A, C, E)$ and transected $(B, D$, $F$ ) Rana catesbeiana's dorsal root ganglion. Note the larger number of cells positive for the NADPH-diaphorase reaction $(B)$, the c-Foslike immunoreactivity in the nucleus of the neuron $(D)$, and the more intense tyrosine hydroxylase-like immunoreactivity surrounding neurons $(F) 3$ days after sciatic nerve transection. Arrows point to neurons positive for NADPH-diaphorase $(A)$ and c-FOS $(C)$. Scale bars: $A$ and $B=20 \mu \mathrm{m}, C=10 \mu \mathrm{m}, D$ and $F=40 \mu \mathrm{m}$.

functional role in frogs. Because total mitochondrial mass and maximum rate of oxygen consumption appear to be directly linked in mammals (38), the increased number of mitochondria found in frog DRG may indicate a higher ability of SGCs to produce energy. This hypothesis was suggested to explain the enlargement of mitochondria in SGCs from mammalian DRG observed after peripheral nerve injury (29). The greater number of ribosomes and RER reinforces the higher activation of SGCs from frog DRG as early as 3 days after SNT. This higher activation of these cells also occurs in mammals (39). Another change that reinforces the activation of SGCs in frog DRG in response to SNT is the increased NADPH-diaphorase reaction in these cells and sensory neurons. In mammals, it was suggested that neuronal NO signals satellite glia in axotomized DRG to neutralize the cytotoxic effect of inducible NO synthase by inducing neurotrophic factors in the glial cell (40). A similar hypothesis may be raised for frogs to explain the increased NADPH-diaphorase reaction in parallel to the ultrastructural changes in SGCs.
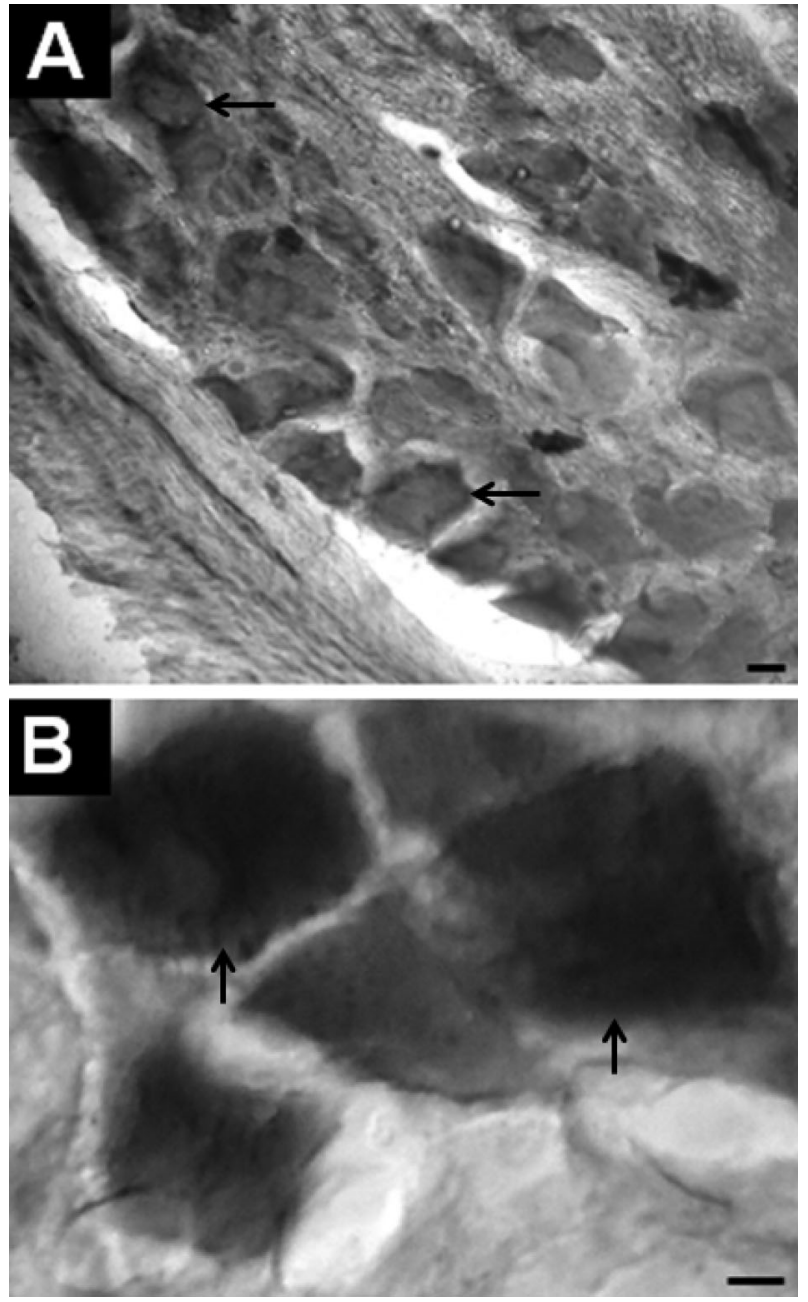

Figure 5. Serotonin- $(A)$ and Glut3-like $(B)$ immunoreactivity in a medium neuron of the dorsal root ganglion from a naive frog Scale bars: $A=20 \mu \mathrm{m} ; B=40 \mu \mathrm{m}$.

Overall, the present study provides evidence that SNT induces ultrastructural, histochemical and immunohistochemical changes in frog DRG that are very similar to those described in mammals. The difference appears to be the beginning of SGC proliferation. Thus, our results support the use of frogs to study the effects of SNT, a model of neuropathic pain, on nervous tissue. The use of frogs in these studies provides knowledge not only about this issue, which still has many unanswered questions, but also about the evolution of these responses in vertebrates.

\section{Acknowledgments}

Research supported by FAPERGS and CNPq. 


\section{References}

1. Ten Donkelaar HJ. Anurans. In: Nieuwenhuys R, Ten Donkellar HJ, Nicholson C (Editors), The central nervous system of vertebrates. Berlin: Springer-Verlag; 1998. p 1151-1314.

2. Matsuda S, Kobayashi N, Terashita T, Shimokawa T, Shigemoto K, Mominoki K, et al. Phylogenetic investigation of Dogiel's pericellular nests and Cajal's initial glomeruli in the dorsal root ganglion. J Comp Neurol 2005; 491: 234245, doi: 10.1002/cne.20713.

3. Crowe MJ, Brown TJ, Bresnahan JC, Beattie MS. Distribution of NADPH-diaphorase reactivity in the spinal cord of metamorphosing and adult Xenopus laevis. Brain Res Dev Brain Res 1995; 86: 155-166, doi: 10.1016/01653806(95)00021-5.

4. Cristino L, Florenzano F, Bentivoglio M, Guglielmotti V. Nitric oxide synthase expression and cell changes in dorsal root ganglia and spinal dorsal horn of developing and adult Rana esculenta indicate a role of nitric oxide in limb metamorphosis. J Comp Neurol 2004; 472: 423-436, doi: 10.1002/cne.20057.

5. Hope BT, Michael GJ, Knigge KM, Vincent SR. Neuronal NADPH diaphorase is a nitric oxide synthase. Proc Natl Acad Sci U S A 1991; 88: 2811-2814, doi: 10.1073/pnas.88.7.2811.

6. Holz GG, Anderson EG. The actions of serotonin on frog primary afferent terminals and cell bodies. Comp Biochem Physiol C 1984; 77: 13-21, doi: 10.1016/0742-8413(84)90124-5.

7. Philippi M, Vyklicky L, Kuffler DP, Orkand RK. Serotoninand proton-induced and modified ionic currents in frog sensory neurons. J Neurosci Res 1995; 40: 387-395, doi: 10.1002/jnr.490400313.

8. Chen Y, Wang AJ, Ma YL. [Effects of morphine on sensitivities of alpha-adrenoceptors in toad spinal ganglion neurons]. Zhongguo Yao Li Xue Bao 1993; 14: 417-420.

9. Stevens CW. Opioid research in amphibians: an alternative pain model yielding insights on the evolution of opioid receptors. Brain Res Brain Res Rev 2004; 46: 204-215, doi: 10.1016/j.brainresrev.2004.07.003.

10. Stevens CW, Brasel CM, Mohan S. Cloning and bioinformatics of amphibian mu, delta, kappa, and nociceptin opioid receptors expressed in brain tissue: evidence for opioid receptor divergence in mammals. Neurosci Lett 2007; 419: 189-194, doi: 10.1016/j.neulet.2007.04.014.

11. Stevens CW, Martin KK, Stahlheber BW. Nociceptin produces antinociception after spinal administration in amphibians. Pharmacol Biochem Behav 2009; 91: 436440, doi: 10.1016/j.pbb.2008.08.022.

12. Chen NC, Srinivasan RC, Shauver MJ, Chung KC. A systematic review of outcomes of fasciotomy, aponeurotomy, and collagenase treatments for Dupuytren's contracture. Hand 2011; 6: 250-255, doi: 10.1007/s11552-0119326-8.

13. Coble DJ, Taylor DK, Mook DM. Analgesic effects of meloxicam, morphine sulfate, flunixin meglumine, and xylazine hydrochloride in African-clawed frogs (Xenopus laevis). J Am Assoc Lab Anim Sci 2011; 50: 355-360.

14. Ohkita M, Saito S, Imagawa T, Takahashi K, Tominaga M, Ohta T. Molecular cloning and functional characterization of Xenopus tropicalis frog transient receptor potential vanilloid 1 reveal its functional evolution for heat, acid, and capsaicin sensitivities in terrestrial vertebrates. J Biol Chem 2012; 287: 2388-2397, doi: 10.1074/jbc.M111.305698.

15. Saito S, Nakatsuka K, Takahashi K, Fukuta N, Imagawa T, Ohta $\mathrm{T}$, et al. Analysis of transient receptor potential ankyrin 1 (TRPA1) in frogs and lizards illuminates both nociceptive heat and chemical sensitivities and coexpression with TRP vanilloid 1 (TRPV1) in ancestral vertebrates. J Biol Chem 2012; 287: 30743-30754, doi: 10.1074/jbc.M112.362194.

16. Partata WA, Cerveira JF, Xavier LL, Viola GG, Achaval M. Sciatic nerve transection decrease substance $P$ immunoreactivity in the lumbosacral spinal cord of the frog (Rana catesbeiana). Comp Biochem Physiol B Biochem Mol Biol 2002; 131: 807-814, doi: 10.1016/S1096-4959(02)00041-6.

17. Guedes RP, Marchi MI, Viola GG, Xavier LL, Achaval M, Partata WA. Somatostatin-, calcitonin gene-related peptide, and gamma-aminobutyric acid-like immunoreactivitity in the frog lumbosacral spinal cord: distribution and effects of sciatic nerve transection. Comp Biochem Physiol B Biochem Mol Biol 2004; 138: 19-28, doi: 10.1016/j.cbpc.2004.01.004.

18. Guedes RP, Marchi MI, Achaval M, Partata WA. Complete sciatic nerve transection induces increase of neuropeptide $Y$ like immunoreactivity in primary sensory neurons and spinal cord of frogs. Comp Biochem Physiol A Mol Integr Physiol 2004; 139: 461-467, doi: 10.1016/j.cbpb.2004.10.006.

19. Hansen N, Uceyler N, Palm F, Zelenka M, Biko L, Lesch KP, et al. Serotonin transporter deficiency protects mice from mechanical allodynia and heat hyperalgesia in vincristine neuropathy. Neurosci Lett 2011; 495: 93-97, doi: 10.1016/ j.neulet.2011.03.035.

20. Joseph L, Butera RJ. High-frequency stimulation selectively blocks different types of fibers in frog sciatic nerve. IEEE Trans Neural Syst Rehabil Eng 2011; 19: 550-557, doi: 10.1109/TNSRE.2011.2163082.

21. Stark B, Carlstedt T, Cullheim S, Risling M. Developmental and lesion-induced changes in the distribution of the glucose transporter Glut-1 in the central and peripheral nervous system. Exp Brain Res 2000; 131: 74-84, doi: 10.1007/s002219900300.

22. Soares HD, Chen SC, Morgan JI. Differential and prolonged expression of Fos-lacZ and Jun-lacZ in neurons, glia, and muscle following sciatic nerve damage. Exp Neurol 2001; 167: 1-14, doi: 10.1006/exnr.2000.7558.

23. Keilhoff G, Fansa H, Wolf G. Nitric oxide synthase, an essential factor in peripheral nerve regeneration. Cell Mol Biol 2003; 49: 885-897.

24. Lukacova N, Cizkova D, Krizanova O, Pavel J, Marsala M, Marsala J. Peripheral axotomy affects nicotinamide adenine dinucleotide phosphate diaphorase and nitric oxide synthases in the spinal cord of the rabbit. J Neurosci Res 2003; 71: 300-313, doi: 10.1002/jnr.10470.

25. Hanani M. Satellite glial cells in sensory ganglia: from form to function. Brain Res Rev 2005; 48: 457-476, doi: 10.1016/ j.brainresrev.2004.09.001.

26. Arkhipova SS, Raginov IS, Mukhitov AR, Chelyshev YA. Satellite cells of sensory neurons after various types of sciatic nerve trauma in the rat. Neurosci Behav Physiol 2010; 40: 609-614, doi: 10.1007/s11055-010-9303-7.

27. Humbertson A Jr, Zimmermann E, Leedy M. A chronological study of mitotic activity in satellite cell hyperplasia associated 
with chromatolytic neurons. Z Zellforsch Mikrosk Anat 1969; 100: 507-515, doi: 10.1007/BF00344371.

28. Pannese E. The structure of the perineuronal sheath of satellite glial cells (SGCs) in sensory ganglia. Neuron Glia Biol 2010; 6: 3-10, doi: 10.1017/S1740925X10000037.

29. Hanani M. Satellite glial cells in sympathetic and parasympathetic ganglia: in search of function. Brain Res Rev 2010; 64: 304-327, doi: 10.1016/j.brainresrev.2010.04.009.

30. McDougal DB Jr, Holowach J, Howe MC, Jones EM, Thomas CA. The effects of anoxia upon energy sources and selected metabolic intermediates in the brains of fish, frog and turtle. J Neurochem 1968; 15: 577-588, doi: 10.1111/ j.1471-4159.1968.tb08956.x.

31. Oliveira AL. Apoptosis of sensory neurons and satellite cells after sciatic nerve transection in C57BL/6J mice. Braz J Med Biol Res 2001; 34: 375-380, doi: 10.1590/S0100879X2001000300012.

32. Atlasi MA, Mehdizadeh $M$, Bahadori MH, Joghataei MT. Morphological identification of cell death in dorsal root ganglion neurons following peripheral nerve injury and repair in adult rat. Iran Biomed J 2009; 13: 65-72.

33. Lukacova N, Davidova A, Kolesar D, Kolesarova M, Schreiberova A, Lackova M, et al. The effect of N-nitro-Larginine and aminoguanidine treatment on changes in constitutive and inducible nitric oxide synthases in the spinal cord after sciatic nerve transection. Int $\mathrm{J} \mathrm{Mol}$ Med 2008; 21: 413-421.

34. Lin CT, Tsai YJ, Chen SH, Wang HY, Lin LH, Lue JH. Early expression of injury-induced neuropeptide $Y$ in primary sensory neurons and the cuneate nucleus in diabetic rats with median nerve transection. J Chem Neuroanat 2010; 40: 102-111, doi: 10.1016/j.jchemneu.2010.05.006.

35. Wang D, Gao Y, Ji H, Hong Y. Topical and systemic administrations of ketanserin attenuate hypersensitivity and expression of CGRP in rats with spinal nerve ligation. Eur $J$ Pharmacol 2010; 627: 124-130, doi: 10.1016/ j.ejphar.2009.11.011.

36. Brumovsky PR, Seroogy KB, Lundgren KH, Watanabe M, Hokfelt T, Gebhart GF. Some lumbar sympathetic neurons develop a glutamatergic phenotype after peripheral axotomy with a note on VGLUT(2)-positive perineuronal baskets. Exp Neurol 2011; 230: 258-272, doi: 10.1016/j.expneurol. 2011.05.004

37. Xia CM, Colomb DG Jr, Akbarali HI, Qiao LY. Prolonged sympathetic innervation of sensory neurons in rat thoracolumbar dorsal root ganglia during chronic colitis. Neurogastroenterol Motil 2011; 23: 801-e339, doi: 10.1111/j.1365-2982.2011.01728.x.

38. Hoppeler H, Hudlicka O, Uhlmann E. Relationship between mitochondria and oxygen consumption in isolated cat muscles. J Physiol 1987; 385: 661-675.

39. Liu FY, Sun YN, Wang FT, Li Q, Su L, Zhao ZF, et al. Activation of satellite glial cells in lumbar dorsal root ganglia contributes to neuropathic pain after spinal nerve ligation. Brain Res 2012; 1427: 65-77, doi: 10.1016/j.brainres.2011.10.016.

40. Bradman MJ, Arora DK, Morris R, Thippeswamy T. How do the satellite glia cells of the dorsal root ganglia respond to stressed neurons? Nitric oxide saga from embryonic development to axonal injury in adulthood. Neuron Glia Biol 2010; 6: 11-17, doi: 10.1017/S1740925X09990494. 